\title{
Distribution and Turnover
}

\author{
of Cholesterol in Humans
}

\author{
Paul J. Nestel, H. Malcolm Whyte, and DeWitt S. Goodman \\ From the Department of Clinical Science, The John Curtin School of Medical \\ Research, The Australian National University, Canberra, Australia, and The \\ Department of Medicine, Columbia University College of Physicians and \\ Surgeons, New York 10032
}

A B S T R A C T The relationships between some parameters of cholesterol metabolism and body weight were studied in 22 subjects. Cholesterol $-4-{ }^{14} \mathrm{C}$, complexed with plasma lipoprotein, was injected intravenously and from the resultant specific activity-time curves a number of indexes of cholesterol turnover were calculated. These were based on the two-pool model previously described by Goodman and Noble and included estimates of the sizes of the two pools, the production rate of cholesterol in the system, the rate constants for cholesterol removal from the two pools and transfer between the pools, and the metabolic clearance of cholesterol.

Single and multiple regression analysis was used to define the relationships between the turnover and distribution of cholesterol and the total weight and fat content of the body.

The amount of cholesterol in the more rapidly turning over pool $\mathrm{A}$, which probably includes cholesterol in liver, plasma, erythrocytes, and part of the viscera such as intestine, varied from 14.9 to $32.7 \mathrm{~g}$. The mean value for the extraplasma part of pool A was $17.9 \mathrm{~g}$. Making certain assumptions it was possible to derive estimates of the probable lower and upper values for size of pool $B$ (exchangeable cholesterol in tissues other than in pool A), which were, on average, 35 and $60 \mathrm{~g}$. The daily production rate of cholesterol (assumed to be equivalent to total turnover rate) varied between 0.73 and 1.68 g/day.

The production rate of cholesterol and the size of pool B were significantly related to total body, and particularly to excess body, weight. When the plasma content was excluded, the amount of cholesterol in pool A was not related to weight. For a body of ideal weight the production rate was $1.10 \mathrm{~g} / \mathrm{day}$ and the size of pool $\mathrm{B}$

Received for publication 27 August 1968 and in revised form 14 February 1969. between 32 and $53 \mathrm{~g}$. For each kilogram of excess weight the expected increments were $0.0220 \mathrm{~g} /$ day and $0.90 \mathrm{~g}$, respectively.

The plasma cholesterol concentration was not related to the production rate or to the amount of cholesterol in the two pools. It was, however, inversely related to the fractional rate of removal from pool $\mathrm{A}$ and to the metabolic clearance rate of cholesterol which suggests that inadequate excretion could be of importance in the development of hypercholesterolemia.

\section{INTRODUCTION}

Of the many factors which influence the plasma cholesterol concentration the significance of body weight and fatness remains unresolved. Among earlier observations, the study by Tanner (1) is unique in its demonstration of a highly significant correlation between skinfold thickness and serum cholesterol levels in healthy young men. Other studies of this nature have reported relationships between fatness and serum cholesterol which were either barely significant (2) or clearly of no significance $(3-5)$. Two recent studies $(6,7)$ using large populations have shown significant relationships, at least in certain age groups. Thus, Montoye, Epstein, and $\mathrm{Kjelsberg} \mathrm{(6)} \mathrm{in} \mathrm{a} \mathrm{survey} \mathrm{of} \mathrm{a} \mathrm{population} \mathrm{of} 6500$ found low but statistically significant relationships between serum cholesterol and body fatness especially between the ages of 15 and $45 \mathrm{yr}$. A smaller study by Rifkind and Begg (7) of some 400 healthy individuals and 97 men with arterial disease of the legs, also demonstrated significant relationships between the logarithm of the serum cholesterol concentration and relative body weight among men 40-59.yr of age. It is possible however, that measures of cholesterol metabolism other than its concentration in the plasma may be more closely related to body weight and fatness. 
The amount of cholesterol present in plasma represents only a small proportion of total body cholesterol and it may bear little relationship to the turnover of cholesterol in the plasma or in the body as a whole. Thus, Nestel and Monger (8) were unable to demonstrate a significant relationship between the concentration and the turnover rate of plasma esterified cholesterol, and Goodman and Noble (9) similarly failed to find a correlation between the serum cholesterol concentration and the production rate of cholesterol contained in a body pool which included plasma. On the other hand, a significant relationship has been observed between the turnover rate of plasma esterified cholesterol and body surface area (8).

The possibility that body fatness may be related to some of the dynamic aspects of cholesterol metabolism in the body has been examined in the present study by using the model for cholesterol turnover reported by Goodman and Noble (9).

\section{METHODS}

22 subjects were studied, of whom six were in New York and are included from the series reported by Goodman and Noble (9). The subjects ate their usual diet and maintained constant weight throughout the study. None was taking a cholesterol-lowering drug. Apart from two normal subjects (R. N. and R. O.) all had hyperlipidemia and/or coronary heart disease.

Cholesterol-4- ${ }^{14} \mathrm{C}$, complexed with plasma lipoprotein, was injected intravenously and the specific activity of plasma free, esterified, and total cholesterol ${ }^{1}$ measured at least three times in the first week and that of total cholesterol weekly for about 10 wk using the methods described fully elsewhere $(9,10)$. The resultant plasma cholesterol specific radioactivity-time curves could be resolved precisely into two exponential functions (Fig. 1) indicating that the turnover of plasma cholesterol conforms to a two-pool model (Fig. 2). The results were used to calculate a variety of parameters based on the kinetic analysis of two-pool systems in equilibrium as expounded by Gurpide, Mann, and Sandberg (11) and as shown to apply to cholesterol metabolism by Goodman and Noble (9). In essence this depicts two pools: pool A is a rapidly turning over pool of cholesterol, presumably in the liver, plasma, erythrocytes, and probably including some of the cholesterol in the intestine and other viscera, and pool $\mathrm{B}$ is a slowly turning over pool, probably related to the remainder of the cholesterol in the viscera and to that in skeletal muscle, skin, and adipose tissue (12). So that appropriate degrees of confidence can be attached to various calculations made in the present study it is im-

\footnotetext{
${ }^{1}$ Since plasma free and esterified cholesterol reached isotopic equilibrium after the fourth day in the 16 subjects in whom this was studied (C. A. to C. D., Table I), the specific radioactivity of free cholesterol was equal to that of total cholesterol in all except the first (day 2) and very occasionally in the second (day 4) samples in which the specific radioactivity of free cholesterol exceeded that of total cholesterol. The calculations for the two-pool model excluded these discrepant points, so that the calculations were based on an analysis of the specific activity of plasma total cholesterol vs. time.
}

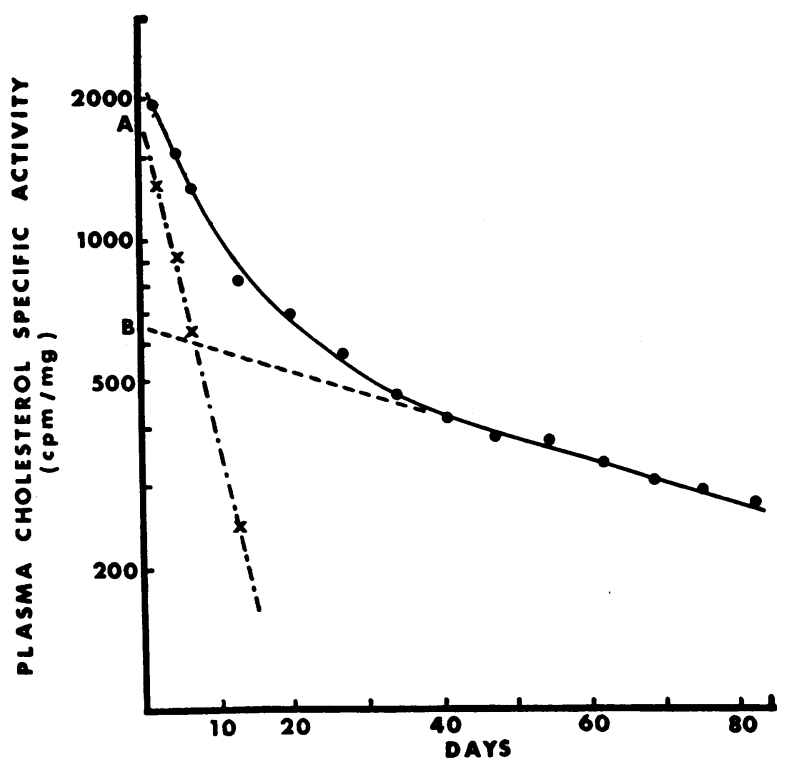

Figure 1 A typical plasma free cholesterol specific radioactivity-time curve followed for 82 days and resolved into two exponential functions. $\mathrm{A}$ and $\mathrm{B}$ are the $\mathrm{Y}$ intercepts of the two exponentials.

portant to have a clear understanding of the assumptions involved in the model used.

The basic model is illustrated in Fig. 2. The labeled cholesterol is introduced into pool A and serial samples taken from the same pool for measurements of specific radioactivity. Analysis of the specific radioactivity-time curve yields the values of several constants from which the following meaningful parameters can be determined: $M_{\Delta}$, the size of pool $\mathrm{A} ;-k_{\Delta \Delta}$, the rate constant for total removal of cholesterol from pool $\mathrm{A}$, which includes transfer into pool $\mathrm{B}$ $\left(k_{\mathrm{AB}}\right)$ plus excretion from pool $\mathrm{A}\left(k_{\mathrm{A}}\right) ;-k_{\mathrm{BB}}$, the rate constant for total removal of cholesterol from pool $B$, which includes transfer into pool A $\left(k_{\mathbf{B A}}\right)$ plus excretion from pool $\mathrm{B}\left(k_{\mathrm{B}}\right) ; \mathrm{PR}$, the production rate, or rate of introduction of "new" cholesterol into pool A, excluding recycled material originating in pool A and returning from pool B; and MCR, the metabolic clearance rate of cholesterol from pool A, expressed as a volume of plasma and calculated as the production rate divided by the plasma concentration of total cholesterol. We have subdivided $\mathrm{M}_{\mathbf{\Delta}}$ into the amount

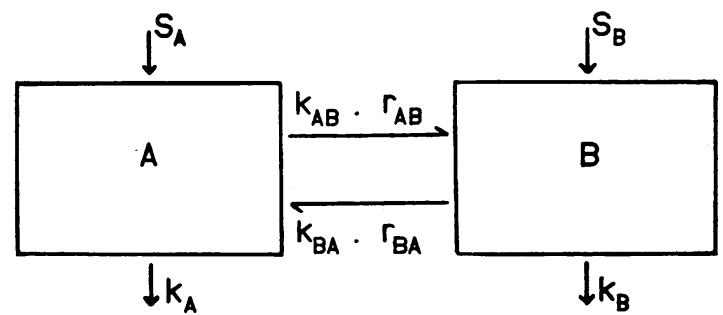

FIGURE 2 The basic two-pool model showing the rates of entry of material into the pools $\left(S_{A}\right.$ and $\left.S_{B}\right)$, the rate constants $(k)$ and rates $(r)$ of losses from each pool or of transfer of material between the pools. 
contained in plasma, $M_{\Delta P}$, and the amount contained in other tissues, $M_{\Delta x}$, by assuming the plasma volume to be $40 \mathrm{ml} / \mathrm{kg}$ of body weight.

Since it can be inferred from current knowledge of cholesterol catabolism that loss of cholesterol from pool B other than through pool $\mathrm{A}$ is likely to be very small in relation to that lost from pool A (13-15), Goodman and Noble have assumed that $k_{\mathbf{B}}=0$. Under these circumstances and assuming steady-state conditions, the total production rate is $P R=S_{A}$ $+S_{B}=r_{\Delta}$ (the rate of excretion from pool A) and it is possible to calculate the following additional parameters: $k_{\mathrm{EA}}$, the rate constant for transfer of cholesterol from pool B to pool $\mathrm{A} ; k_{\mathrm{A}}$, the rate constant for excretion of cholesterol from pool $\mathrm{A}$ and from the whole system; and $k_{\mathrm{AB}}$, the rate constant for movement of cholesterol from pool A to pool B. Since $M_{A}$ is already known, estimates can then be made of the rate of the loss of cholesterol from the system $\left(r_{A}=\right.$ $\left.k_{\mathrm{A}} \cdot \mathrm{M}_{\mathrm{A}}\right)$ and of the rate of transfer from $\mathrm{A}$ to $\mathrm{B}\left(\mathrm{r}_{\mathrm{AB}}=\right.$ $\left.k_{\mathrm{AB}} \cdot \mathrm{M}_{\mathbf{A}}\right)$.

The one important item missing is an estimate of the size of pool B. The rate of entry of material into pool B rilust, in steady-state conditions, equal the rate at which it leaves it: that is $\mathrm{S}_{\mathrm{B}}+\mathrm{r}_{\mathrm{AB}}=\mathrm{r}_{\mathrm{BA}}$. Since $\mathrm{M}_{\mathbf{B}}=\mathrm{r}_{\mathrm{BA}} / k_{\mathrm{B} A}$ and $r_{B A}=P R-S_{A}+r_{A B}$, then $M_{B}=\left(P R-S_{A}+r_{A B}\right) / k_{B A}$.

Thus, $M_{B}$ could be calculated if $S_{A}$ were known; and assumptions about $S_{A}$ can be made which make it possible to give reasonable estimates of lower and higher limiting values for $M_{B}$. On the one hand the lowest value for $M_{B}\left(M_{B 1}\right)$ would be obtained if $S_{A}=P R$, that is, when there is no synthesis of cholesterol by the tissues which comprise pool B $\left(\mathrm{S}_{\mathrm{B}}=0\right)$. On the other hand an upper value $\left(\mathrm{M}_{\mathrm{B} 2}\right)$ would be achieved when $S_{A}$ is minimal. Since $S_{A}$ represents the sum of cholesterol synthesized in pool A plus that derived from the diet and since a reasonable value for daily absorption of cholesterol is $200 \mathrm{mg} /$ day in man (15), $\mathbf{M}_{\mathbf{B} 2}$ has been calculated on the assumption that $S_{A}=0.2 \mathrm{~g} /$ day; that is, that there is no synthesis of cholesterol by the tissues in pool $\mathrm{A}$. The mean $\left(M_{\mathbf{B M}}\right)$ of these two extreme values has been used in calculating most of the correlation and regression relationships and for estimating the rate of movement of cholesterol from $\mathrm{B}$ to $\mathrm{A}\left(\mathrm{r}_{\mathrm{BA}}=k_{\mathrm{BA}} \cdot \mathrm{M}_{\mathrm{BM}}\right)$ and the rate of synthesis in $B\left(S_{B}=r_{B A}-r_{A B}\right)$.

The "ideal" weight for each subject has been taken to be the average weight for subjects $20-24$ yr of age of the same sex and height (16). The difference between this and the actual body weight has been called "excess weight." Standard methods of analysis and for calculating regression equations have been used (17).

\section{RESULTS}

Table I gives some of the pertinent characteristics of the subjects and the principal estimated parameters of cholesterol metabolism. All other parameters referred to in this paper can be derived from them. The regression relationships between these parameters and serum cholesterol and body weight which were of prime interest are given in Table II. It was especially important to examine the multiple regressions because body weight and plasma cholesterol concentrations were negatively correlated in this group of subjects: $r=-0.655, P<$ 0.01 .

$\mathrm{M}_{\mathbf{A}}$, the total amount of cholesterol in pool $\mathrm{A}$, was significantly related to body weight and plasma cho- lesterol concentration. This is to be expected for that part of $M_{\Delta}$ which is in plasma; when this is excluded the remaining part of pool $A, M_{\Delta x}$, bears no definite relationship to these parameters. The estimated values for $\mathrm{M}_{\Delta \mathrm{x}}$ ranged from 8.8 to $23.1 \mathrm{~g}$ (mean $17.9 \mathrm{~g}$ ). Likewise $r_{A B}$, the rate of movement of cholesterol from pool A to pool B, was not significantly related to body weight or cholesterol concentration. Its magnitude varied from 1.09 to $2.24 \mathrm{~g} /$ day (mean 1.47).

The production rate of cholesterol was significantly related to body weight (Fig. 3) and more particularly to excess weight rather than to ideal or standard weight (Fig. 4, Table II). It was not correlated with serum cholesterol concentration or with the size of either pool $A$ or pool B. The suggestion emerges that the total production rate of cholesterol is, on the average, 1.10 $\mathrm{g} /$ day for a person of "ideal" body weight and increases by $0.0220 \mathrm{~g} /$ day for every kilogram of excess body weight. These figures are based on the single regression of production rate on excess weight, as shown in Table II and in Fig. 4. One subject (C.S.) had excess weight which was far above the rather limited range displayed by the other subjects. Omitting this subject from the analysis gave somewhat similar regression relationships, but with reduced significance. Thus, for $\mathrm{n}=21, \mathrm{PR}=$ $1.077+0.0290$ excess weight ( $\mathrm{SE}=0.0120 ; P<0.025)$.

The size of pool B was, also significantly related to total and excess body weight (Table II, Fig. 5) and was calculated to contain about $42.4 \mathrm{~g}$ of cholesterol (or somewhere between $32.0 \mathrm{~g}$ and $52.9 \mathrm{~g}$, which were the mean lower and upper values for $\left.\mathrm{M}_{\mathbf{B}}\right)$ plus $0.90 \mathrm{~g}$ (0.54$1.27 \mathrm{~g}$ ) for every kilogram of excess body weight. Again, omitting the one outstandingly obese patient, re-

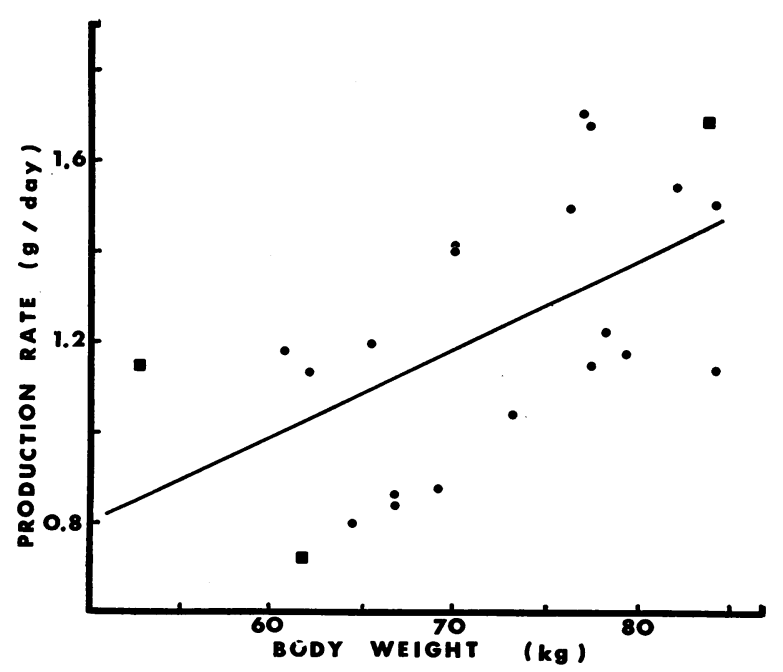

FIGURE 3 Relationship between the production rate of cholesterol and total body weight. Circles refer to male and squares to female subjects. 


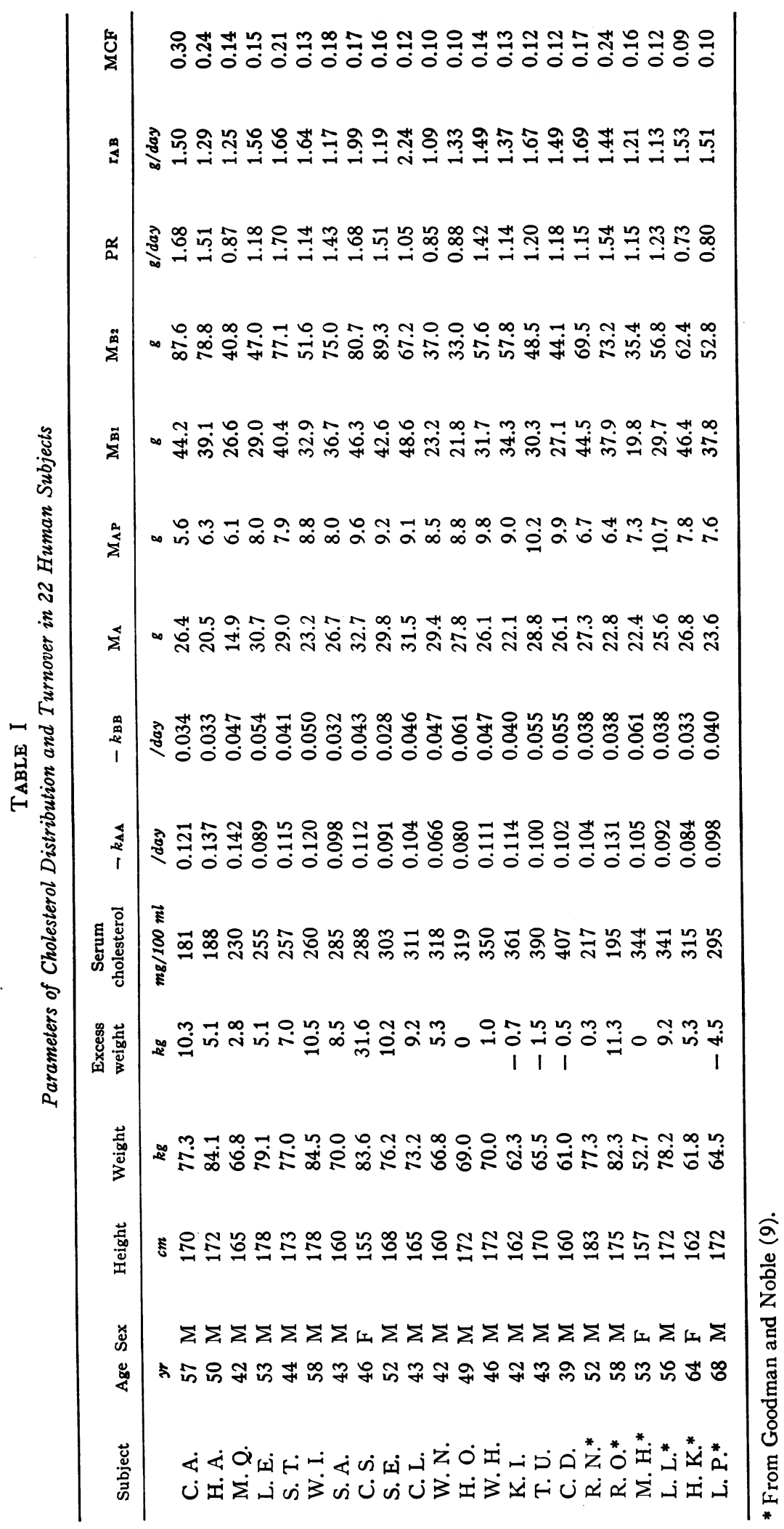




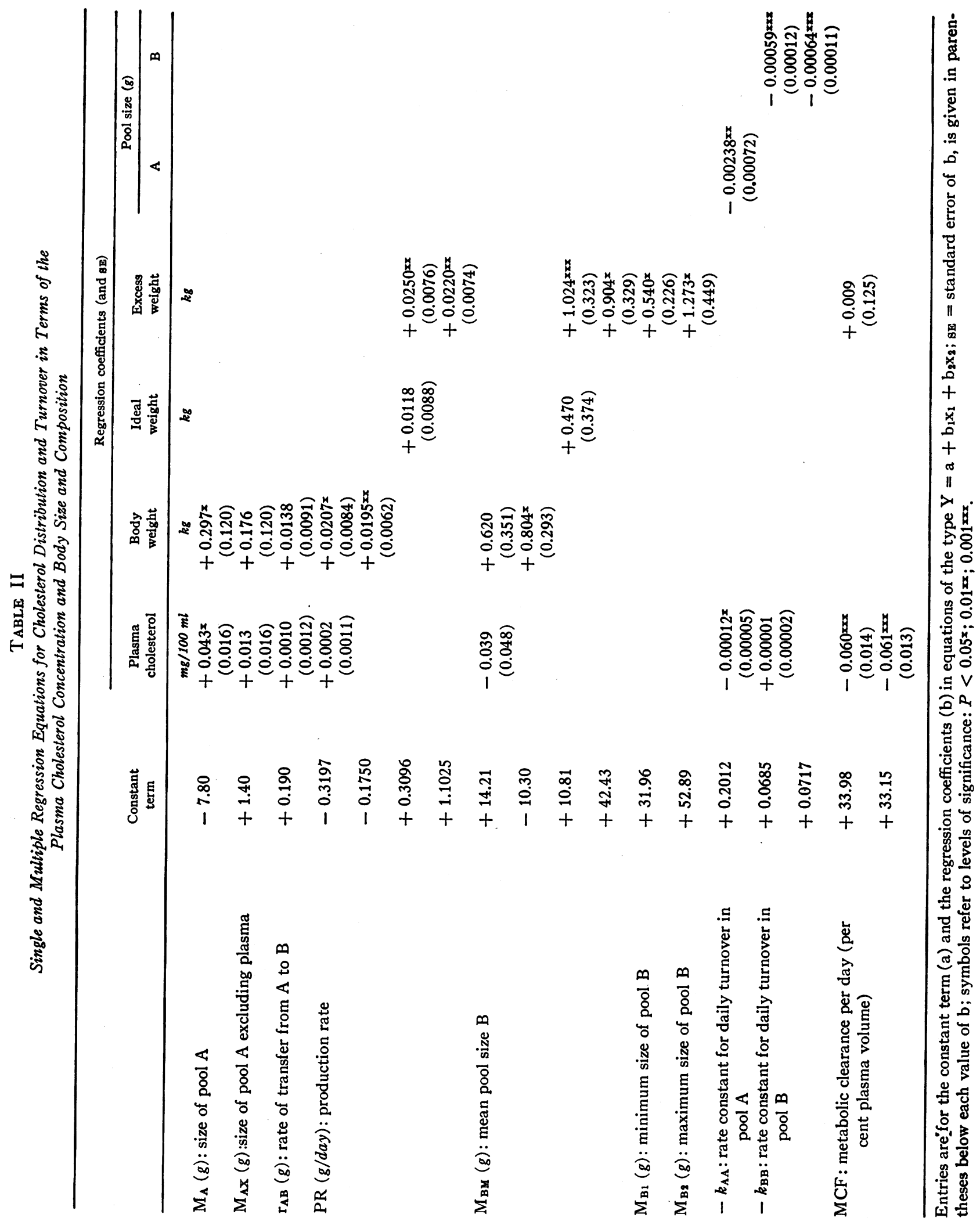




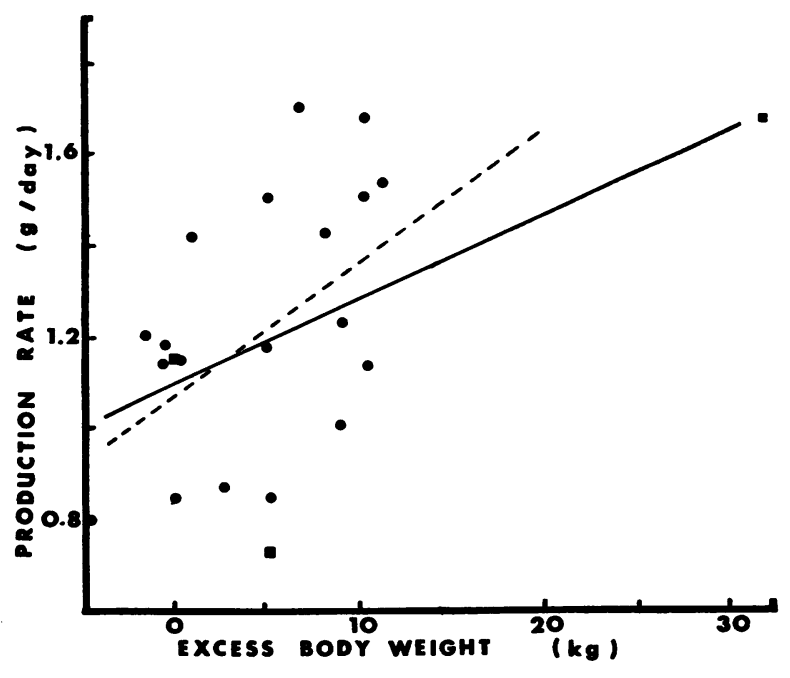

FIGURE 4 Relationship between production rate and excess body weight. Regression lines for $n=22$ (solid line) and for $n=21$ omitting one obese female (interrupted line).

gression relationships were altered only slightly: $\mathrm{M}_{\mathbf{B M}}=$ $40.80+1.347$ excess weight ( $\mathrm{SE}=0.494 ; P<0.02$ ).

The fractional turnover rate for cholesterol in pool A $\left(-k_{\Delta \Delta}\right)$ was inversely related to both the size of pool $A$ and the plasma cholesterol level (Table II, Fig. 6).

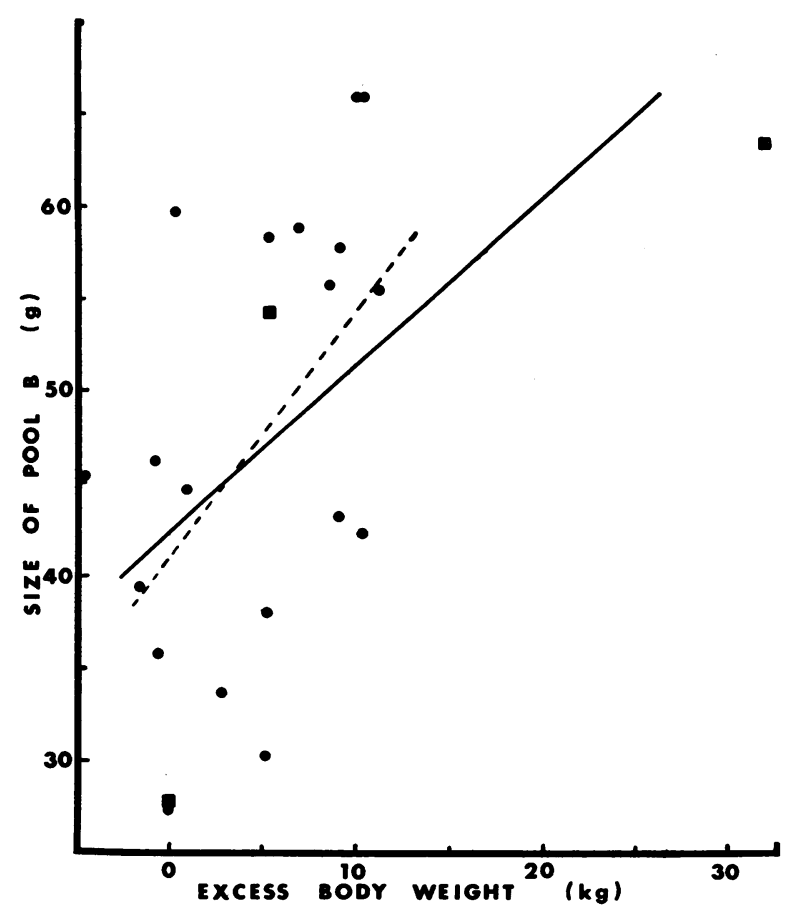

FIGURE 5 Relationship between the size of pool B (mean of upper and lower estimates) and excess body weight. Regression lines for $n=22$ (solid line) and $n=21$ (interrupted line).

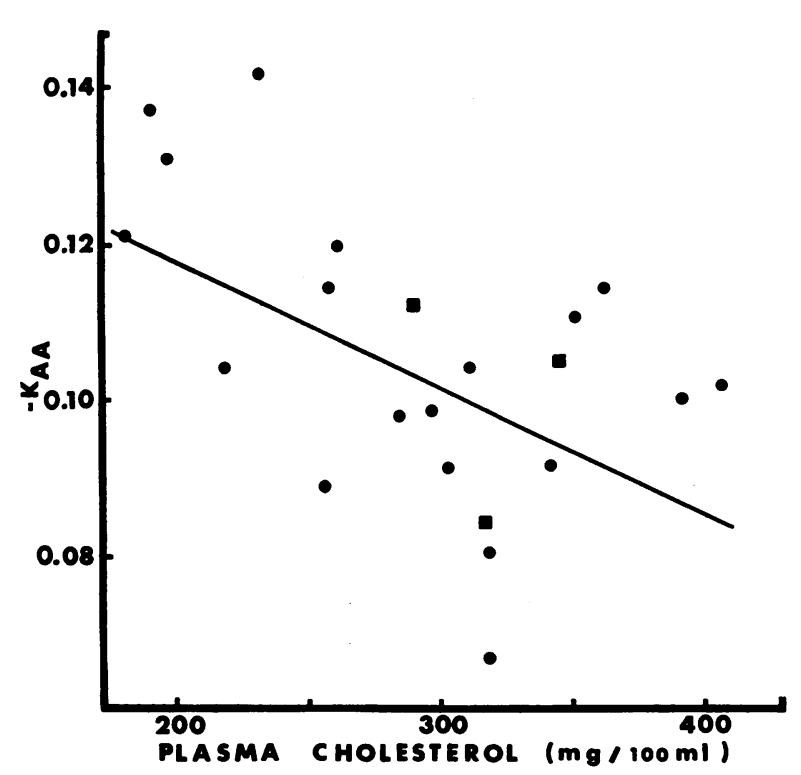

FIgURE 6 Relationship between the fractional turnover rate of cholesterol in pool A and the plasma cholesterol concentration.

The values predicted from the regression equation would be approximately $0.12 /$ day and $0.10 /$ day when the plasma cholesterol level is 200 and $400 \mathrm{mg} / 100 \mathrm{ml}$, respectively. The fractional loss from pool B $\left(-k_{\mathbf{B B}}\right)$ was inversely related to its pool size and was of the order of 0.047 /day for a subject with "ideal" body weight.

The turnover of cholesterol in the whole system can be expressed in terms of "metabolic clearance," either as the volume (MCR) or the fraction (MCF) of plasma "cleared" per day. The latter was found to be unrelated to excess body weight but it was very strongly related inversely to the plasma cholesterol concentration $(P<$ 0.001 , Fig. 7). Predicted values would be $21 \%$ /day and $9 \% /$ day for subjects with plasma cholesterol levels of 200 and $400 \mathrm{mg} / 100 \mathrm{ml}$, respectively.

Using the regression equations in which $P R$ and $M_{3}$ were related to excess body weight and $-k_{\mathrm{BB}}$ was related to the size of pool $\mathrm{B}$, and the mean values for $\mathrm{M}_{\Delta \mathrm{X}}$ and $\mathrm{r}_{\Delta \mathrm{B}}$, it is now possible to construct some hypothetical models of cholesterol metabolism. Examples shown in Fig. 8 illustrate some kinetics of cholesterol metabolism under three sets of circumstances in which the body weight and serum cholesterol are being varied. The main features to be noted are as follows.

1. Ideal weight. At ideal body weight, the total amount of exchangeable cholesterol is about $65 \mathrm{~g}$ with about one-third in pool A and two-thirds in pool B. The plasma cholesterol concentration (and the actual magnitude of the ideal weight, which varies with height) affects this only slightly to the extent by which 


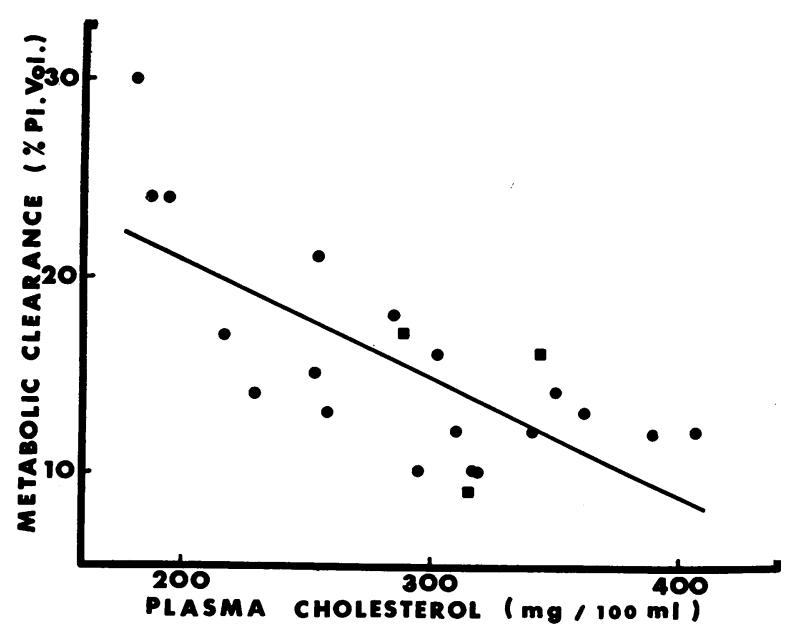

Frgure 7 Relationship between the metabolic clearance of cholesterol as a fraction of the plasma volume and the plasma cholesterol concentration.

it affects the plasma pool. The size of pool B is uncertain but the mean lower and upper values are 32.0 and $52.9 \mathrm{~g}$ : that is, respectively, when cholesterol synthesis in $B$ is zero or when it accounts for the total endogenous production in the body. Thus, the total amount of cholesterol in the two pools of the illustrated model would be between 54.7 and $75.6 \mathrm{~g}$. At ideal body weight the predicted production rate is $1.10 \mathrm{~g} /$ day leaving a daily endogenous production of $900 \mathrm{mg}$, if we assume that 200 $\mathrm{mg}$ of dietary cholesterol is absorbed. If we accept that $\mathrm{r}_{\triangle \mathrm{B}}$ is relatively constant at $1.47 \mathrm{~g} / \mathrm{day}$ and $\mathrm{r}_{\mathrm{BA}}$ is 1.99 $\mathrm{g} /$ day (with limits of 1.47 and 2.89) the endogenous production within pool B would be $520 \mathrm{mg} /$ day (within the limits 0 and 900). Endogenous production in pool A would then be $380 \mathrm{mg}$ /day (with limits of 900 and 0 ).

2. Effect of excess weight. The addition of $20 \mathrm{~kg}$ of excess weight is accompanied by a 73\% increase in endogenous production of cholesterol and by expansion of the body content of cholesterol. The expansion occurs to a small extent in the plasma pool but largely in pool $B$ where the increase is probably of the order of $18.1 \mathrm{~g}$ (10.8-25.4 g).

3. Effect of hypercholesterolemia. Apart from the inevitably increased plasma pool of cholesterol, hypercholesterolemia is not associated with any alteration in the rate of production or the amount and distribution of exchangeable cholesterol. The metabolic clearance rate is decreased: whereas $23 \%$ of the plasma volume is

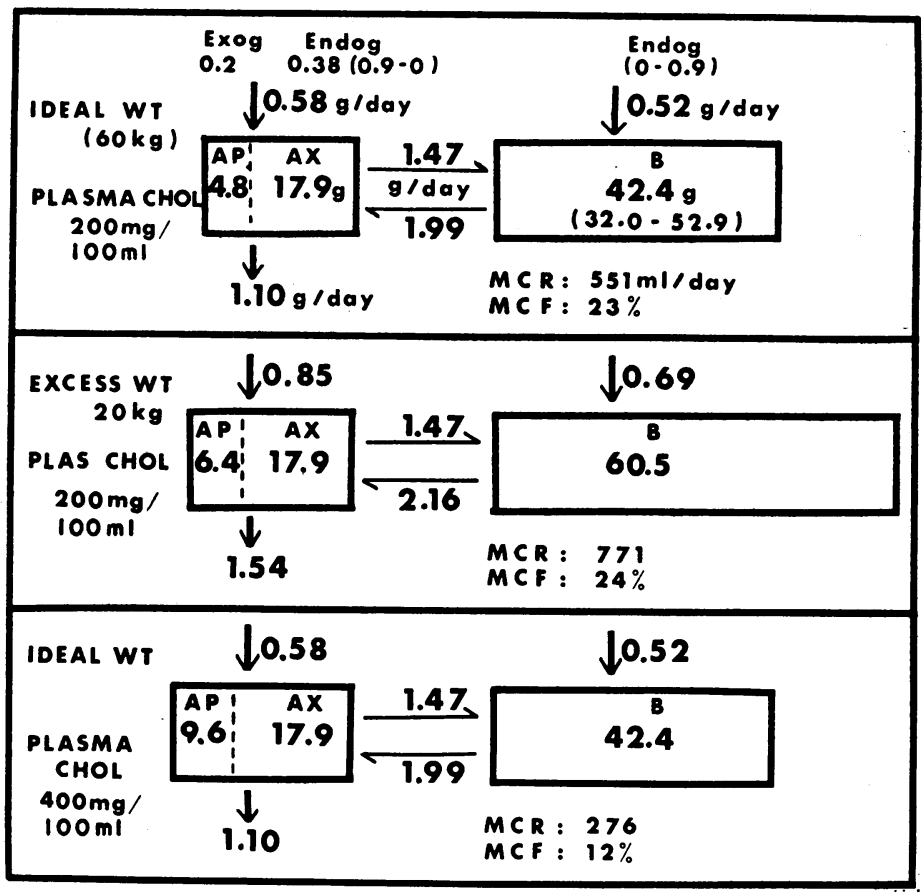

FIgURE 8 Hypothetical models of cholesterol turnover constructed from the calculated values shown in Table I. Effects of body weight on cholesterol metabolism in the absence and presence of hypercholesterolemia. $\mathrm{AP}=$ cholesterol in plasma; $\mathrm{AX}=$ cholesterol in pool $\mathrm{A}$ excluding plasma $; \mathrm{B}=$ cholesterol in pool $\mathrm{B} ; \mathrm{MCR}=$ metabolic clearance rate; $\mathrm{MCF}=$ metabolic clearance fraction. 
"cleared" daily when the serum cholesterol level is 200 $\mathrm{mg} / 100 \mathrm{ml}$, only $12 \%$ is cleared when the level is 400 $\mathrm{mg} / 100 \mathrm{ml}$.

\section{DISCUSSION}

6 of the 22 studies presented in this paper have already been reported by Goodman and Noble (9) who demonstrated that the plasma cholesterol specific activity curve in studies such as this can be resolved into two exponential functions indicating that the turnover of plasma cholesterol conforms to a two-pool model (Figs. 1 and 2 ). This is supported by the results in our 16 additional studies. In addition to those parameters of cholesterol metabolism which have been discussed by Goodman and Noble (9), viz. the size of pool A, the production rate, and the rate constants $k_{\mathbf{A}}$ and $k_{\mathrm{BB}}$ for the total rates of removal of cholesterol from pools A and B, we have also estimated $r_{A B}$ and $r_{B A}$ (the turnover rates of cholesterol between pools A and B), the size of pool B, and some possible values for the rates of synthesis in pools $A$ and $B\left(S_{A}\right.$ and $\left.S_{B}\right)$.

The size of pool $B$, and therefore the values for $\mathrm{r}_{\mathbf{B} A}$, $\mathrm{S}_{\mathbf{A}}$, and $\mathrm{S}_{\mathbf{B}}$ cannot be precisely calculated from the data, but estimates have been made of two values between which it must lie. The reasoning behind these calculations is as follows. Cholesterol is synthesized in most tissues and it is certain that both pools participate in the formation of cholesterol. Since much of the cholesterol in lymph chylomicrons is initially deposited in the liver $(18,19)$ it seems certain that some of the cholesterol entering pool A, which includes the liver, would be derived from the diet. Current belief is that this is equivalent to about $0.2 \mathrm{~g} /$ day (15), and we have assumed that our subjects were absorbing this amount from their diet. An upper estimate of the size of pool B was made by assuming that no synthesis of cholesterol took place in pool A and that all cholesterol which entered pool A had been derived from the diet and from pool B. A lower estimate for the size of pool B was obtained by assuming that no synthesis occurred in that pool, the cholesterol within it having originated wholly in pool A. Neither of these situations is likely to exist in reality since some synthesis of cholesterol would always be expected to occur in tissues of both pools. As discussed by Goodman and Noble (9) pool A presumably includes cholesterol in tissues such as liver, plasma, and erythrocytes, and probably also some of the cholesterol in the viscera such as intestine, spleen, kidney, etc. Since the liver and the small intestine are major sources of circulating cholesterol (20) and since the formation of cholesterol in extrahepatic tissues of primates appears to be only partly suppressible under normal circumstances (21) it is most unlikely that synthesis in pool A would ever be zero. Similarly, although the ability of tissues in pool B to synthesize cholesterol is much less (in terms of production per unit weight of tissue) than that of the tissues in pool A $(20,21)$ it is again unlikely that production in pool B would amount to nothing. Therefore, the two values which we have estimated for pool B must be regarded as hypothetical figures which have no true physiological meaning except that the correct value can be expected to lie somewhere between them. We have accepted the mean of these two values for the sake of simplicity, though it is probable from what has just been said that the actual figure is closer to the minimal value. Even so, the relative contributions from the two pools will depend on the masses of different tissues contained in them, that is, on body composition, and the degree of obesity could be an important factor. It is of some importance, therefore, to note that the higher and the lower estimates are not very far apart and that both these values, as well as their mean, are significantly related to excess body weight.

Arising from these studies is the question of the relationship of hypercholesterolemia to the various parameters of cholesterol metabolism studied and the influence on these of body weight. It so happened that body weight and plasma cholesterol were inversely related in this small group of subjects whereas any significant relationship found in general populations has been a direct one (6). It was nevertheless clear that the serum cholesterol concentration was in general independent of most parameters of cholesterol metabolism. It was notably not correlated with the production rate. Previous work has shown the lack of any demonstrable relationship between the concentration and the turnover rate of plasma esterified cholesterol (8). Major variations can exist, therefore, in the rates of formation and excretion of cholesterol and in the amount of cholesterol contained in the major pools of the body (excluding the plasma) without having any necessary relationship to the level of cholesterol in the plasma.

The plasma cholesterol concentration was, however, inversely related to the fractional rate of loss of cholesterol from pool $\mathrm{A}\left(-k_{\mathrm{AA}}\right)$ and to the total rate of clearance of cholesterol from the body, expressed as a fraction of the plasma volume (MCF, Fig. 7). Thus, higher levels of plasma cholesterol are not associated with any noticeable increase in cholesterol content of other pools nor in the rate at which cholesterol is produced or acquired (or excreted) by the body. It is a natural corollary that fractional loss is inversely related to plasma concentration. These findings raise the possibility that in hypercholesterolemia a steady state is achieved, but with a raised plasma cholesterol level, because of some impediment to the "clearance" or excretion of cholesterol from the plasma pool.

The influence that excess body weight exerts on cho- 
lesterol metabolism was a major finding of this study. Body weight, especially when expressed as excess weight or adiposity, was clearly related to several parameters of cholesterol turnover. Both the production rate (Fig. 4) and the size of pool B (Fig. 5) were directly and significantly correlated with excess weight (Table II). This is perhaps relevant to the rise and fall in serum cholesterol which have been described to occur while weight is being rapidly gained or lost (22). It is worth noting that an association between body weight and the turnover of plasma esterified cholesterol has been observed (8). The present findings cannot be explained on the basis of an increase in body tissues in general since the relationship was solely to excess weight, that is, obese tissue, and not at all to the rest of the body weight. The magnitude of the increase in the size of pool $B$, found to be associated with excess weight in the present study $(0.9 \mathrm{~g} / \mathrm{kg})$, is of the order of what might be expected from the reported cholesterol content of adipose tissue, $1.6 \mathrm{mg} /(0.53-4.15) \mathrm{g}$ (23). In addition, the increase in production rate $(22 \mathrm{mg} /$ day per $\mathrm{kg}$ excess body weight) is similar to the reported rates of cholesterogenesis by adipose tissue in monkeys (21).

The mechanisms through which adiposity influences cholesterol turnover cannot be determined from these studies. Some cholesterol is presumably derived from the products of metabolism of free fatty acids since endogenously synthesized cholesterol is derived from acetate (24). It is interesting therefore that the turnover of plasma free fatty acids, like cholesterol, appears to be related to the degree of body fatness (25, $26)$. Obesity appears to be associated with the preferential utilization of fat for energy as judged from measurements of R.Q. (27) and Dupont has claimed that the utilization of fat for energy results in accelerated cholesterol synthesis in animals (28). The relationship of these factors, however, and of the production of cholesterol by adipose tissue itself (21) to the findings of the present study can only be speculative at this stage.

\section{ACKNOWLEDGMENTS}

We are grateful to Dr. Robert P. Noble for information and advice in regard to part of this work.

These studies were supported in part by the National Heart Foundation of Australia and by Grant AM-05968 from the National Institutes of Health, Bethesda, Md. Dr. Goodman is a Career Scientist of the Health Research Council of the City of New York under Contract I-399.

\section{REFERENCES}

1. Tanner, J. M. 1951. The relation between serum cholesterol and physique in healthy young men. J. Physiol. 115: 371 .

2. Gofman, J. W., and H. B. Jones. 1952. Obesity, fat metabolism and cardiovascular disease. Circulation. 5: 514.
3. Lewis, L. A., F. Olmsted, I. H. Page, E. Y. Lawry, G. V. Mann, F. J. Stare, M. Hanig, M. A. Lauffer, T. Gordon, and F. E. Moore. 1957. Serum lipid levels in normal persons. Findings of a co-operative study of lipoproteins and atherosclerosis. Circulation. 16: 227.

4. Whyte, H. M. 1965. Behind the adipose curtain. Studies in Australia and New Guinea relating to obesity and coronary heart disease. Amer. J. Cardiol. 15: 66.

5. Miller, D. C., M. F. Trulson, M. B. McCann, and P. D. White. 1958. Diet, blood lipids and health of Italian men in Boston. Ann. Intern. Med. 49: 1178.

6. Montoye, H. J., F. H. Epstein, and O. M. Kjelsberg 1966. Relationship between serum cholesterol and body fatness. An epidemiologic study. Amer. J. Clin. Nutr. 18: 397.

7. Rifkind, B. M., and T. Begg. 1966. Relationship between relative body weight and serum lipid levels. Brit. Med. J. 5507: 208 .

8. Nestel, P. J., and E. A. Monger. 1967. Turnover of plasma esterified cholesterol in normocholesterolemic and hypercholesterolemic subjects and its relation to body weight. J. Clin. Invest. 46: 967.

9. Goodman, DeW. S., and R. P. Noble. 1968. The turnover of plasma cholesterol in man. J. Clin. Invest. 47: 231.

10. Nestel, P. J., E. Z. Hirsch, and E. A. Couzens. 1965. The effect of chlorophenoxyisobutyric acid and ethinyl estradiol on cholesterol turnover. J. Clin. Invest. 44: 891.

11. Gurpide, E., J. Mann, and E. Sandberg. 1964. Determination of kinetic parameters in a two-pool system by administration of one or more tracers. Biochemistry. 3: 1250.

12. Chobanian, A. V., and W. Hollander. 1962. Body cholesterol metabolism in man. I. The equilibration of serum and tissue cholesterol. J. Clin. Invest. 41: 1732.

13. Spritz, N., E. H. Ahrens, Jr., and S. Grundy. 1965. Sterol balance in man as plasma cholesterol concentrations are altered by exchanges of dietary fats. J. Clin. Invest. 44: 1482.

14. Goodman, DeW. S. 1965. Cholesterol ester metabolism. Physiol. Rev. 45 : 747.

15. Wilson, J. D., and C. A. Lindsey, Jr. 1965. Studies on the influence of dietary cholesterol on cholesterol metabolism in the isotopic steady state in man. J. Clin. Invest. 44: 1805.

16. Society of Actuaries. 1959. Build and blood pressure studies. Chicago.

17. Fisher, R. A. 1950. Statistical methods for research workers. Oliver \& Boyd Ltd. Edinburgh.

18. Nestel, P. J., R. J. Havel, and A. Bezman. 1963. Metabolism of constituent lipids of dog chylomicrons. J. Clin. Invest. 42: 1313.

19. Goodman, DeW. S. 1962. The metabolism of chylomicron cholesterol ester in the rat. J. Clin. Invest. 41: 1886.

20. Wilson, J. D. 1968. Biosynthetic origin of serum cholesterol in the squirrel monkey: evidence for a contribution by the intestinal wall. J. Clin. Invest. $47: 175$.

21. Dietschy, J. M., and J. D. Wilson. 1968. Cholesterol synthesis in the squirrel monkey: relative rates of synthesis in various tissues and mechanisms of control. J. Clin. Invest. 47: 166.

22. Galbraith, W. B., W. E. Connor, and D. B. Stone. 1964. Serum lipid changes in obese subjects given reducing 
diets of varied cholesterol content. Clin. Res. 12: 352. (Abstr.)

23. Khan, B., G. E. Cox, and K. Asdel. 1963. Cholesterol in human tissues. Arch. Pathol. 76: 369.

24. Bloch, K., and D. Rittenberg. 1942. On the utilization of acetic acid for cholesterol formation. J. Biol. Chem. 145: 625.

25. Issekutz, B., W. M. Bortz, H. I. Miller, and P. Paul. 1968. Turnover rate of plasma FFA in humans and in dogs. Metabolism. 16: 1001.
26. Nestel, P. J., and H. M. Whyte. 1968. Plasma free fatty acid and triglyceride turnover in obesity. Metabolism. 17: 1122.

27. Shapiro, J., W. Peck, E. Buskirk, P. Mueller, R. Thompson, and G. D. Whedon. 1964. Metabolic responses of normal and obese subjects to intravenous glucose and insulin. Clin. Res. 12: 280. (Abstr.)

28. Dupont, J. 1965. Relationship between utilization of fat and synthesis of cholesterol and total lipid in young female rats. J. Amer. Oil Chem. Soc. 42: 903. 